\title{
Expression of $\mathrm{mdm} 2$ and $\mathrm{p} 53$ in epithelial neoplasms of the colorectum
}

\author{
X-P Hao, T Günther, A Roessner, A B Price, I C Talbot
}

\begin{abstract}
Aims-To evaluate the respective roles of mdm2 (murine double minute 2) and p53 in the development of colorectal carcinoma.

Methods-Formalin fixed, paraffin wax embedded tissues from 72 sporadic adenomas and 55 carcinomas were investigated by means of immunohistochemistry for $\mathrm{mdm} 2$ and $\mathrm{p} 53$.

Results-mdm2 was expressed weakly in 17 of $72(23.6 \%)$ adenomas and in 14 of 55 $(25.4 \%)$ carcinomas. p53 was expressed in 19 of $72(26.4 \%)$ adenomas and in 23 of 55 $(41.8 \%)$ carcinomas. Four adenomas and five carcinomas showed positive staining for both proteins. Overexpression of p53 in adenomas was associated with moderate and severe dysplasia but not with tumour size. No associations were found between the expression of $\mathrm{mdm} 2$ and either the degree of dysplasia or tumour size. In carcinomas, neither the expression of p53 nor mdm2 correlated with Dukes's stage, metastasis, or differentiation. No associations were found between the expression of p53 and $\mathrm{mdm} 2$ in either adenomas or carcinomas.

Conclusions-Although mdm2 has been reported to be an oncogene, it does not appear to play a major role in the development of colorectal carcinoma.

(f Clin Pathol:Mol Pathol 1998;51:26-29)
\end{abstract}

Keywords: mdm2; p53; colorectal carcinoma

The mdm2 gene (murine double minute 2) was originally found to be amplified and overexpressed in a mouse BALB/c 3T3 cell line, ${ }^{1}$ and was later shown to enhance the tumorigenic potential of cells when overexpressed. ${ }^{2}$ Thus, mdm 2 has been regarded as an oncogene. It has been mapped to chromosome 12q13-14 and encodes a cellular phosphoprotein that contains p53 binding domains. Analysis of the $\mathrm{mdm} 2$ amino acid sequence suggests that it is a transcriptional modulator, ${ }^{2}$ and in vitro experiments have found that the gene product can interact with both wild-type and mutant p53. ${ }^{3}$ It has been shown that loss of the $\mathrm{mdm} 2$ gene in mice results in early embryonic lethality in animals carrying a functional p53 gene, but deletion of the p53 gene in mdm2 null mice enables the mice to survive and develop normally, suggesting that $\mathrm{mdm} 2$ is an important negative regulator of the growth inhibitory activities of p53 in vivo. ${ }^{4}{ }^{5} \mathrm{mdm} 2$ has also been reported to interact with transcriptional factor $\mathrm{E} 2 \mathrm{~F} 1 / \mathrm{DP} 1$ and with $\mathrm{pRb}$ (the retinoblastoma gene product), both of which are involved in regulating cell growth. ${ }^{67}$ Amplification or overexpression of $\mathrm{mdm} 2$ has been found in a variety of human stromal and epithelial malignancies such as sarcomas, ${ }^{89}$ gliomas, ${ }^{10}$ leukaemias, ${ }^{11}$ lymphomas, ${ }^{12}$ and breast and lung carcinomas, ${ }^{13}{ }^{14}$ and it has been correlated with an increased potential for malignancy. However, no detailed investigations of the overexpression of $\mathrm{mdm} 2$ in colorectal tumours have been reported. To shed light on the role of $\mathrm{mdm} 2$ relative to $\mathrm{p} 53$ in colorectal cancer, the present study aims to examine the changes in expression of these two proteins in a series of sporadic colorectal adenomas and carcinomas.

\section{Methods}

TISSUES

Seventy two patients with sporadic adenomas, 55 patients with sporadic adenocarcinomas, and normal mucosa from 16 cases of noninflamed diverticular disease were selected from the histopathology files of St Mark's Hospital. Eighty five areas of histologically normal mucosa adjacent to either the adenoma or carcinoma were also analysed in this series. All specimens had been fixed in unbuffered $10 \%$ formal saline for 12-24 hours. Serial sections were cut at $4 \mu \mathrm{m}$ from paraffin wax embedded blocks and placed on poly-L-lysine coated (Sigma Chemicals, St Louis, Missouri, USA) slides. One slide was stained with haematoxylin and eosin for histological classification, and the others were used for immunostaining.

IMMUNOHISTOCHEMISTRY

Immunohistochemistry was performed in this series using a standard ABC method. Briefly, tissue sections were dewaxed in xylene and rehydrated in graded alcohol to distilled water. To block endogenous peroxidase activity, slides were incubated for 30 minutes in $0.3 \%$ hydrogen peroxide in methanol. Sections were then subjected to antigen retrieval by boiling for 10 minutes in an aluminium pressure cooker at 15 pounds per sqaure inch in sodium citrate buffer (0.01 M, pH 6.0). Subsequently, nonspecific staining was blocked by incubation with normal horse serum for 10 minutes. Following this, anti-mdm 2 protein mouse monoclonal antibody (1/70 dilution in phosphate buffered saline (PBS); Novocastra Laboratories, Newcastle upon Type, UK) was added to the sections, with incubation overnight at room temperature. A second layer of biotinylated monoclonal horse antimouse immunoglobin $\mathrm{G}$ (1/200 dilution for 30 minutes; Vector Laboratories, Burlingame, California, USA) was applied, and followed by a final layer of Vectastain 


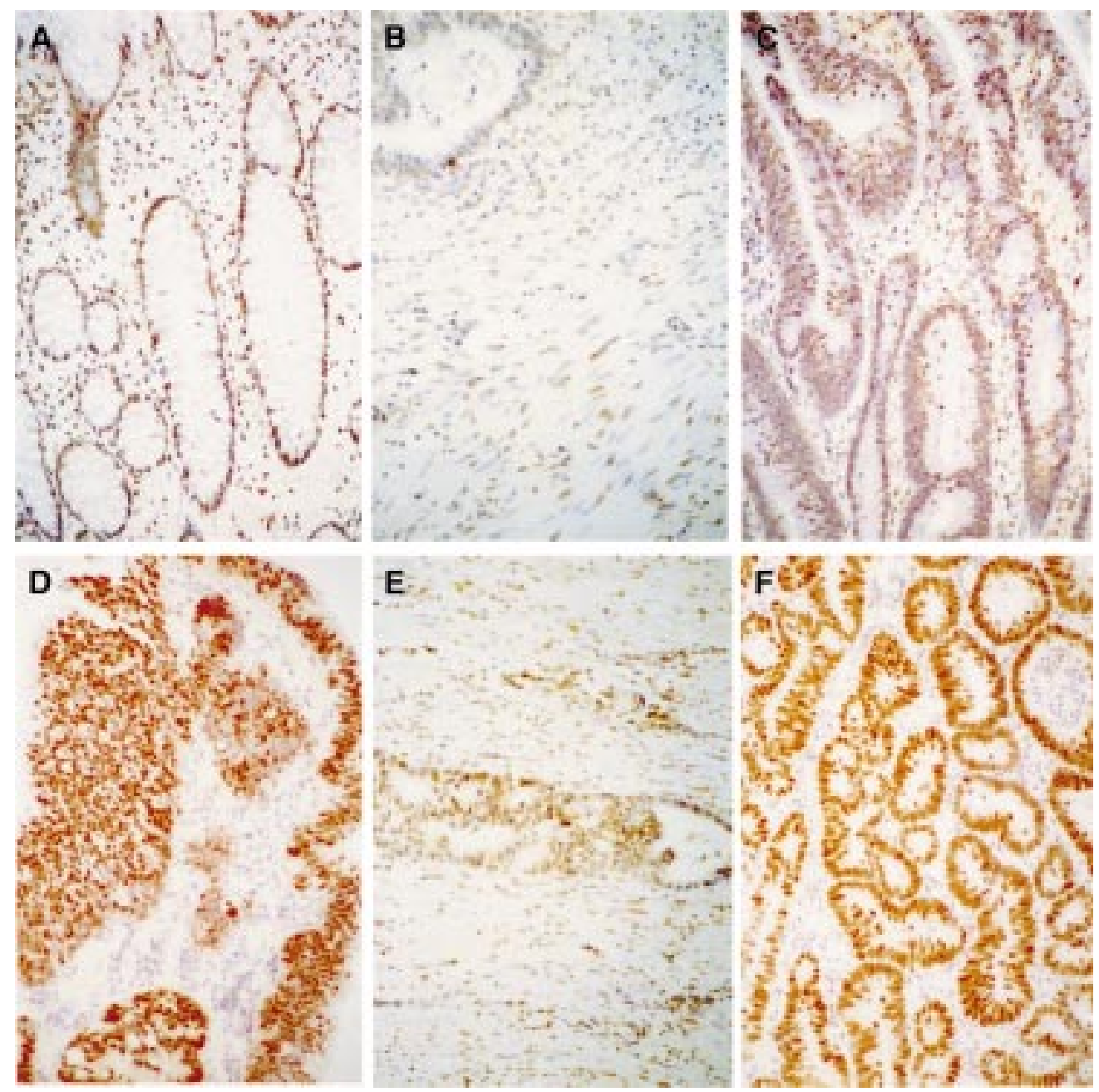

Figure 1 (A) Normal epithelial cells and the mononuclear cells in the stroma showing nuclear immunostaining for mdm2. (B) Smooth muscle cells showing positive nuclear staining while carcinomatous cells show negative staining for mdm2. (C) Adenomatous epithelium with moderate dysplasia showing nuclear immunostaining for mdm2. (D) Adenomatous epithelium with moderate dysplasia showing strong nuclear immunostaining for $p 53$. The epithelial cell sheets are the result of tangential sectioning. (E) Carcinomatous cells showing weak nuclear staining for mdm2. Note the stromal cells showing positive staining. (F) Carcinomatous cells showing strong nuclear staining for p53. (Original magnifications $\times 50$.)

Elite $\mathrm{ABC}$ kit (1/50 dilution for 30 minutes; Vector Laboratories). 3-3'diaminobenzidine was used as the chromogen. The same procedure was used for $\mathrm{p} 53$ using a $1 / 100$ dilution of the monoclonal antibody Do-7 (Dako, High Wycombe, Bucks, UK). Sections from a uterine leiomyosarcoma and a breast carcinoma were used as positive controls for $\mathrm{mdm} 2$ and $\mathrm{p} 53$, respectively. Negative controls were obtained by replacing the primary antibody with PBS.

\section{SCORING METHODS}

The immunohistochemistry slides were evaluated independently by two observers $(\mathrm{XPH}$ and TG) who were blind to the categorisation of the tumours. The whole slide was examined and the percentage of tumour cells that showed nuclear staining was scored. Twenty per cent was taken as the cut off point to define positivity for $\mathrm{mdm} 2,{ }^{9}$ and $10 \%$ as the threshold of positivity for $\mathrm{p} 53$. The two sets of results were correlated and in the event of disagreement the slides were reviewed together and a consensus reached.
STATISTICS

The $\chi^{2}$ test was used to examine the associations between either mdm 2 or p53 expression and clinicopathological factors (such as tumour size, degree of dysplasia, differentiation). Fisher's exact test was used to assess the correlations between $\mathrm{mdm} 2$ and p53 in both adenomas and carcinomas. Statistical significance was defined as $\mathrm{p} \leqslant 0.05$.

\section{Results}

\section{NORMAL TISSUES}

Normal mucosa from non-inflamed diverticular disease in 3 of $16(18.8 \%)$ cases, and adjacent to an adenoma or carcinoma in 15 of 85 $(17.6 \%)$ cases showed positive staining for mdm2 (fig 1A). There was no statistical difference between $\mathrm{mdm} 2$ expression in adenomas or carcinomas and adjacent normal epithelial cells (both $\mathrm{p}>0.1$; table 1 ). Furthermore, 31 of $127(24.4 \%)$ adenomas and carcinomas also contained positively stained lymphocytes and stromal cells, including some smooth muscle cells. In some cases, smooth muscle cells showed nuclear accumulation 
Table 1 mdm2 expression in normal, adenomatous, and carcinomatous tissues

\begin{tabular}{llll}
\hline & $+v e$ & $-v e$ & $p$ \\
\hline Normal mucosa & 15 & 85 & $>0.1^{\star}$ \\
Adenoma & 17 & 55 & $>0.1 \dagger$ \\
Carcinoma & 14 & 41 & $>0.75 \ddagger$ \\
\hline
\end{tabular}

^Normal mucosa $v$ adenoma; †Normal mucosa $v$ carcinoma; $\ddagger$ Adenomas $v$ carcinoma.

Table 2 Expression of $m d m 2$ and $p 53$ in colorectal adenomas

\begin{tabular}{|c|c|c|c|c|c|c|}
\hline & \multicolumn{3}{|c|}{$m d m 2$} & \multicolumn{3}{|l|}{$p 53$} \\
\hline & $+v e$ & $-v e$ & $p$ & $+v e$ & $-v e$ & $p$ \\
\hline \multicolumn{7}{|l|}{ Size } \\
\hline$\leqslant 1 \mathrm{~cm}$ & 8 & 18 & $>0.25$ & 4 & 22 & $>0.10$ \\
\hline$>1 \mathrm{~cm}$ & 9 & 37 & & 15 & 31 & \\
\hline \multicolumn{7}{|l|}{ Dysplasia } \\
\hline Mild & 7 & 16 & & 1 & 22 & \\
\hline Moderate & 7 & 26 & $>0.50$ & 10 & 23 & 0.005 \\
\hline Severe & 3 & 13 & & 8 & 8 & \\
\hline
\end{tabular}

Table 3 Correlation between mdm2 and p53 in colorectal adenomas and carcinomas

\begin{tabular}{|c|c|c|c|c|}
\hline \multirow[b]{3}{*}{$m d m 2$} & \multicolumn{4}{|l|}{$p 53$} \\
\hline & \multicolumn{2}{|c|}{ Adenomas } & \multicolumn{2}{|c|}{ Carcinomas } \\
\hline & $+v e$ & $-v e$ & $+v e$ & $-v e$ \\
\hline$+v e$ & 4 & 13 & 5 & 9 \\
\hline$-v e$ & 15 & 40 & 18 & 23 \\
\hline$p$ & $>0.75$ & & $>0$. & \\
\hline
\end{tabular}

Table 4 Expression of $m d m 2$ and $p 53$ in colorectal carcinomas

\begin{tabular}{|c|c|c|c|c|c|c|}
\hline & \multicolumn{3}{|c|}{$m d m 2$} & \multicolumn{3}{|l|}{$p 53$} \\
\hline & $+v e$ & $-v e$ & $p$ & $+v e$ & $-v e$ & $p$ \\
\hline \multicolumn{7}{|l|}{ Dukes's stage } \\
\hline A & 8 & 24 & & 11 & 21 & \\
\hline B & 3 & 10 & $>0.50$ & 6 & 7 & $>0.10$ \\
\hline $\mathrm{C}$ & 3 & 7 & & 6 & 4 & \\
\hline \multicolumn{7}{|l|}{ Differentiation } \\
\hline Well & 7 & 12 & & 7 & 12 & \\
\hline Moderate & 7 & 27 & $>0.25$ & 15 & 19 & $>0.75$ \\
\hline Poorly & 0 & 2 & & 1 & 1 & \\
\hline \multicolumn{7}{|l|}{ Metastases } \\
\hline With metastasis & 3 & 8 & 0.90 & 7 & 4 & $>0.10$ \\
\hline No metastasis & 11 & 33 & & 16 & 28 & \\
\hline
\end{tabular}

while adenomatous or carcinomatous epithelium was negative (fig 1B). All non-neoplastic tissues were negative for $\mathrm{p} 53$.

ADENOMAS

The immunoreactivities of $\mathrm{mdm} 2$ and $\mathrm{p} 53$ are shown in tables 2 and $3 . \mathrm{mdm} 2$ immunoreactive cells were seen in 17 of $72(23.6 \%)$ adenomas. All positive cells showed nuclear staining but this was generally weak. No cytoplasmic staining was seen (fig 1C). There were no associations between $\mathrm{mdm} 2$ expression and either the grade of dysplasia or tumour size. p53 immunoreactivity was detected in 19 of 72 (26.4\%) adenomas (fig 1D). p53 overexpression was associated with moderate and severe dysplasia $(p=0.005)$ but not with tumour size. Four cases $(5.6 \%)$ showed positivity for both $\mathrm{mdm} 2$ and p53 (table 3 ). There was no correlation between expression of $\mathrm{mdm} 2$ and p53 (table 3). There was also no significant difference between $\mathrm{mdm} 2$ expression in adenomas and carcinomas ( $p>0.75$; table 1$)$.
CARCINOMAS

Fourteen of the 55 carcinomas $(25.4 \%)$ expressed $\mathrm{mdm} 2$ (fig $1 \mathrm{E})$, while $23(41.8 \%)$ were positive for p53 (fig $1 \mathrm{~F}$ ) (table 4). Five cases $(9.1 \%)$ were immunoreactive for both proteins (table 3 ). Neither mdm 2 nor p53 were associated with clinicopathological factors such as Dukes's stage, differentiation, or metastasis. No differences in p53 overexpression were found between carcinomas and adenomas with respect to moderate and severe dysplasia (table 5). There was also no correlation between the expression of $\mathrm{mdm} 2$ and p53 in carcinomas (table 3).

\section{Discussion}

Using immunohistochemistry, the mdm 2 protein was detected in $23.6 \%$ of adenomas and $26.4 \%$ of carcinomas. This is less frequent than is found in breast $(40.9 \%)$ and bronchogenic carcinomas $(63 \%) .{ }^{13} 14$ As is seen in breast carcinoma, ${ }^{13}$ no associations were detected between overexpression of $\mathrm{mdm} 2$ and any clinicopathological parameters; however, in bronchial carcinoma, ${ }^{14}$ soft tissue sarcoma, ${ }^{9}$ and osteosarcoma, ${ }^{15} \mathrm{mdm} 2$ overexpression is related to reduced differentiation and greater metastatic potential. In the present study, the positive cases showed only weak staining and a low percentage of positive cells. No significant differences in $\mathrm{mdm} 2$ expression were detected between adenomas and carcinomas or between adenomas or carcinomas and adjacent normal epithelial cells. In addition, normal mucosa from non-inflamed diverticular disease, and lymphocytes, stromal cells, and smooth muscle cells in tumour tissues also showed some positive staining. Therefore, as is the situation in cervical cancer, ${ }^{16} \mathrm{mdm} 2$ does not seem to play an important role in colorectal carcinogenesis.

The tumour suppressor gene p53 is a transcriptional activator that regulates cell growth and differentiation. Mutations of the p53 gene are common in human malignancies, including colorectal carcinoma, in which such mutations are thought to be late events. ${ }^{17}$ p53 immunoreactivity was not found in any normal epithelia adjacent to the adenomas or carcinomas or in tissue from non-inflamed diverticular disease. p53 staining was detected in $26.4 \%$ of adenomas and $41.8 \%$ of carcinomas. This is in line with previous studies. ${ }^{18}{ }^{19}$ p53 nuclear accumulation begins to appear at the stage of mild dysplasia, but it is increased significantly in moderate and severe dysplasia. No difference was found between carcinomas and adenomas with moderate and severe dysplasia. This suggests that $\mathrm{p} 53$ mutations may occur at the moderately and severely dysplastic stages in adenoma development.

The consequence of the interaction between $\mathrm{mdm} 2$ and $\mathrm{p} 53$ remains obscure. Previous studies have shown that overexpression of the mdm2 gene can abolish the transactivating capability of the p53 protein, leading to the overexpression of $\mathrm{p} 53 .^{20}$ On the other hand, overexpression of p53 can induce $\mathrm{mdm} 2$ mRNA and protein expression. A reciprocal relation between p 53 and $\mathrm{mdm} 2$ has been proposed as a mechanism for regulating the cell 
cycle. ${ }^{3}$ Recent research has suggested that mdm2 expression can also lead to the rapid degradation of both wild-type and mutant p53. ${ }^{2122}$ These conflicting results may be related to different isoforms of $\mathrm{mdm} 2^{14}$ interacting with p53 or to different interacting domains in $\mathrm{mdm} 2$ or the $\mathrm{p} 53$ protein. ${ }^{23}$ Hence, the relation between $\mathrm{mdm} 2$ and p 53 is complex and is not understood fully at the moment. In this study, we did not find any correlation between the expression of $\mathrm{mdm} 2$ or p53 in either adenomas or carcinomas. It is possible that the interaction between p53 and mdm2 depends on cell type, ${ }^{24}$ so that the results of this interaction might also vary in different types of tissues. Further investigations are under way to clarify the molecular relation between p53 and $\mathrm{mdm} 2$ in colorectal tumours.

1 Cahilly-Snyder L, Yang-Feng T, Francke, U, et al. Molecular analysis and chromosomal mapping of amplified gene isolated from a transformed mouse 3T3 cell line. Somat Cell Mol Genet 1987;13:235-44.

2 Fakharzadeh SS, Trusko SP, George DL. Tumourigenic potential associated with enhanced expression of a gene that is amplified in a mouse tumour cell line. EMBO $f$ 1991;10:1565-9.

3 Momand J, Zambetti GP, Olson DC, et al. The mdm2 oncogene product forms a complex with the $\mathrm{p} 53$ protein and inhibits 553 -mediated transactivation. Cell 1992;69: $1237-45$.

4 Montes de Oca Luna R, Wager DS, Lozano G. Rescue of early embryonic lethality in mdm-2-deficient mice by deletion of p53. Nature 1995;378:203-6.

5 Jones SN, Roe AE, Donehower LA, et al. Rescue of embryonic lethality in mdm-2-deficient mice by absence of p53. onic lethality in mdm-2-der

6 Martin K, Trouche D, Hagemeier C, et al. Stimulation of E2F1/DP1 transcriptional activity by mdm2 oncoprotein. Nature 1995;375:691-4

7 Xiao ZX, Chen JD, Levine AJ, et al. Interaction between the retinoblastoma protein and the oncoprotein MDM2. Nature 1995;375:694-8.
8 Oliner GD, Kinzler KW, Meltzer PS, et al. Amplification of a gene encoding a p53-associated protein in human sarcoa gene encoding a p53-associatc
mas. Nature 1992;358:80-3.

9 Cordon-Cardo C, Latres E, Drobnjak M, et al. Molecular abnormalities of mdm 2 and p53 genes in adult soft tissue sarcomas. Cancer Res 1994;54:794-9.

10 Reifenberger G, Liu L, Ichimura K, et al. Amplification and overexpression of mdm 2 gene in a subset of human malignant gliomas without p53 mutations. Cancer Res 1993;53: 2736-9.

11 Watanabe $\mathrm{T}$, Hotta $\mathrm{T}$, Ichikawa $\mathrm{A}$, et al. The $\mathrm{mdm} 2$ oncogene overexpression in chronic lymphocytic leukemia and low-grade lymphoma of B-cell origin. Blood 1994;84: 3158-65.

12 Martinez JC, Mateo M, Sánchez-beato M, et al. MDM2 expression in lymphoid cells and reactive and neoplastic expression in lymphoid cells and reactive and neoplastic
lymphoid tissue. Comparative study with p53 expression. $\mathcal{F}$ Pathol 1995;177:27-34.

13 Marchetti A, Buttitta F, Girlando S, et al. mdm2 gene alterations and $\mathrm{mdm} 2$ protein expression in breast carcinomas. F Pathol 1995;175:31-8

4 Gorgoulis VG, Zoumpourlis V, Rassidakis GZ, et al. A molecular and immunohistochemical study of the mdm2 protein isoforms and p53 gene product in bronchogenic carcinomas. F Pathol 1996;180:129-37.

15 Ladanyi $\mathrm{M}$, Cha $\mathrm{C}$, Lewis $\mathrm{R}$, et al. MDM2 gene amplification in metastatic osteosarcoma. Cancer Res 1993; 53:16-18.

16 Kessis TD, Slebos RJ, Han SM, et al. p53 gene mutations and $\mathrm{mdm} 2$ amplification are uncommon in primary carcinomas of the uterine cervix. Am f Pathol 1993;143:1398-405.

17 Fearon ER, Vogelstein B. A genetic model for colorectal tumourigenesis. Cell 1990;61:759-67.

18 Pignatelli M, Stamp GWH, Kafiri F, et al. Overexpression of p53 nuclear oncoprotein in colorectal adenomas. Int $\mathcal{f}$ Cancer 1992;50:683-8.

19 Sinicrope FA, Ruan SB, Cleary KR, et al. bcl-2 and p53 oncoprotein expression during colorectal tumourigenesis. Cancer Res 1995;55:237-41.

20 Olson D, Marechal V, Momand J, et al. Identification and characterisation of multiple $\mathrm{mdm} 2$ proteins and $\mathrm{mdm} 2 /$ p53 protein complexes. Oncogene 1993;8:2353-60.

21 Haupt Y, Maya R, Kazaz A, et al. Mdm2 promotes the rapid degradation of p53. Nature 1997;387:296-9.

22 Kubbutat MHG, Jones SN, Vousden KH. Regulation of p53 stability by mdm2. Nature 1997:387:299-303.

23 Chen J, Wu X, Lin J, et al. mdm2 inhibits the G1 arrest and Chen J, Wu X, Lin J, et al. mdm 2 inhibits the G1 arrest and
apoptosis functions of the p53 tumour suppressor protein. apoptosis functions of the $\mathrm{p} 53$ t

24 Momand J, Zambetti GP. Analysis of the proportion of $\mathrm{p} 53$ bound to $\mathrm{mdm}-2$ in cells with defined growth characteristics. Oncogene 1996;12:2279-89. 